\title{
The concept of hydrogen-methane blends storage in underground mine excavations - gas permeability of concrete
}

\author{
D. Gajda, ${ }^{1}$ S. Liu ${ }^{2}$, M. Lutyński ${ }^{1}$ \\ ${ }^{1}$ Silesian University of Technology, Faculty of Mining, Safety Engineering and Industrial \\ Automation, Department of Mining, Poland \\ ${ }^{2}$ Pennsylvania State University, Department of Energy and Mineral Engineering, United States
}

\begin{abstract}
Power-to-gas technology gives the possibility to store the excess power from renewable energy sources by converting electrical energy into gas such as eg. hydrogen. There is however a problem with accessibility of sites where pure hydrogen can be stored. Hence, the idea of blending hydrogen with methane and use underground mine excavations to increase the storage capacity, apart from salt caverns. However, hydrogen has strong capability to diffuse through different materials, including steel and some minerals. The paper proposes a concept of hydrogen/methane blends storage in abandoned underground mine excavations. Research is focused on permeability of concrete as a barrier for stored gases. Gas permeability from two methods: pulse - decay and steady - state, were compared. Gas permeability of investigated concrete and geopolymers depends on the composition and pressure conditions, including axial stress. A significant improvement of tightness of the concrete can be achieved, using a synthetic compounds.
\end{abstract}

\section{Introduction}

Power-to-gas technology has a great potential for future energy storage. It can increase the efficiency of the current renewable energy sources by storing the energy from overproduction when the energy consumption is lower than the production. The overproduced energy at the low demanding period can be used to convert hydrogen and/or methane. Both hydrogen and methane can be stored for future energy harvest. Both hydrogen and methane can be not only utilized for future power generation, but also for other energy demanding purposes, like transportation or industry utilization. Power-to-gas technology gives the opportunity to raise the renewable energy production to the highest possible level while reducing the conventional fossil energy production with their undesirable by-products, like depletion of the natural resources and greenhouse gases emissions. The conventional fossil energy is still fuelling the world to support the wellbeing and the production of energy seems to be unthreatened. But in the future, when the mankind will face the deficiency of fossil fuels, the hydrogen energy can become the most promising alternative. The main problem of this technology is the limited storage 
possibility for hydrogen. Solving the storage problems is the key issue for developing the unconventional energy for sustainable utilization [1].

Hydrogen is considered as an alternative fuel and an energy carrier [2]. Overproduced renewable energy could be converted to hydrogen as the energy carrier through electrolysis process. Because the hydrogen is a gaseous energy and it has high volume per energy unit. Similar to the natural gas, the storage of hydrogen is one of the practical obstacles for largescale energy conversion, storage and harvesting. One possible solution is to blend hydrogen with methane and use current natural infrastructure to store hydrogen along with methane to enrich its energy density [3]. A few previous studies were conducted and demonstrated the possibilities of using the existing natural gas infrastructure for hydrogen-methane blends transport and storage when hydrogen concentration is below certain acceptable level [4].

Blending hydrogen with natural gas generates some technical problems at each stage throughout the process, including pipeline transportation, underground storage, end-use installations (like gas turbines) and control and measurement appliances. One pivot challenge is the small size of hydrogen atom, which diffuses through the metal and mineral structures, even in neutral temperature and pressure conditions [5]. Resistance of natural gas infrastructure to hydrogen differs depending on the element. Some of the elements, like pipelines, tanks and some measure appliances, are more hydrogen-proof, and can be used without adaptations with hydrogen concentration even up to $30 \%$. Some other appliances, like gas turbines, measurement appliances and distribution elements, are more sensitive even for a trivial concentration of hydrogen, even less than $10 \%$ [5]. On the other hand, the Underground Storage Sites are susceptible to the hydrogen, and due to the lack of knowledge about the tolerated hydrogen concentrations, the underground storage sites for hydrogen/methane blends are strongly limited [6].

The purpose of this study is to evaluate the possibility of adapting the abandoned underground mine excavations as the natural gas/hydrogen storage sites. It would be an alternative method for hydrogen storage, and a chance to use the existing underground and surface infrastructures of the mines, which are already or about to be closed. Secondary use of the abandoned mines as the gas storage site would extend the portfolio of mine reclamation methods.

\section{Literature survey and state-of-the-art storage of hydrogen}

There are known and existing underground natural gas storage sites around the world. Storage option depends on regional geology and operational conditions [7]. Three main types of underground gas storage categories are currently in operation: depleted oil/gas reservoirs, aquifers and salt caverns. All kind of mentioned storage sites have been considered to be developed and used for hydrogen storage. Some other storage options are also available in their early stages: abandoned coal mines, lined rock caverns and refrigerated mined caverns. There are three examples of storing natural gas in abandoned coal mines. Storage sites of that kind have been reported in Belgium (Peronnes and Anderlus Coal Mines) and United States (Leyden Coal Mine in Colorado) [8]. These alternative solutions can become popular in the regions without conventional geological storage sites, like depleted oil/gas reservoirs and salt structures. However, adapting each of the mentioned storage options for hydrogen creates new practical challenges, like loss of hydrogen caused by diffusion, chemical reactions, and microbial activity.

Most of currently used underground storage facilities for hydrogen are in subsurface salt caverns. There are a few operating facilities of this kind in North America and Europe. The salt cavern storage is the most reliable and mature method. Acceptable hydrogen concentration is $55 \%$ with the rest $45 \%$ of methane, without any adaptations or R\&D works. Salt caverns, due to their their outstanding natural sealing properties of salt 
minerals, seem to be the best solution for hydrogen storage. Strongest feature is at the same time its weakness. That kind of hydrogen storage sites are limited by the presence of geological salt structures (domes) in convenient for storage locations. What is more, the lack of underground excavations or wells in salt structures makes the drilling and leaching works necessary. Solution mining could take up to $40 \%$ of all the construction costs (including surface infrastructure) [9]. On the other hand, the most problematic underground storage are aquifers. The problems refer to the leakages, risk of hydrate creation and microbial development.

Surface infrastructure for hydrogen production from renewables overproduction and salt caverns storage was the subject of HESTOR Project (Institute of Power Engineering and Turbomachinery [Electronic resource]), performed at the Silesian University of Technology. The scheme of hydrogen production using renewable energy sources is presented in Figure 1. The electrolysis process powered from renewables overproduction can be used, followed by temporary storage of produced energy as the hydrogen/methane blend, and utilize of the stored energy as the fuel in transportation, industry, or secondary electric power production in gas turbines. Electrolyzers for hydrogen production are still in its development stage. There are alkaline cells on advanced level of development, and Polymer Electrolyte Membrane (PEM) and Solid Oxide Electrolyzers (SOE), which are at demonstrative and development levels. Storage issues were not the subject of that project [11].

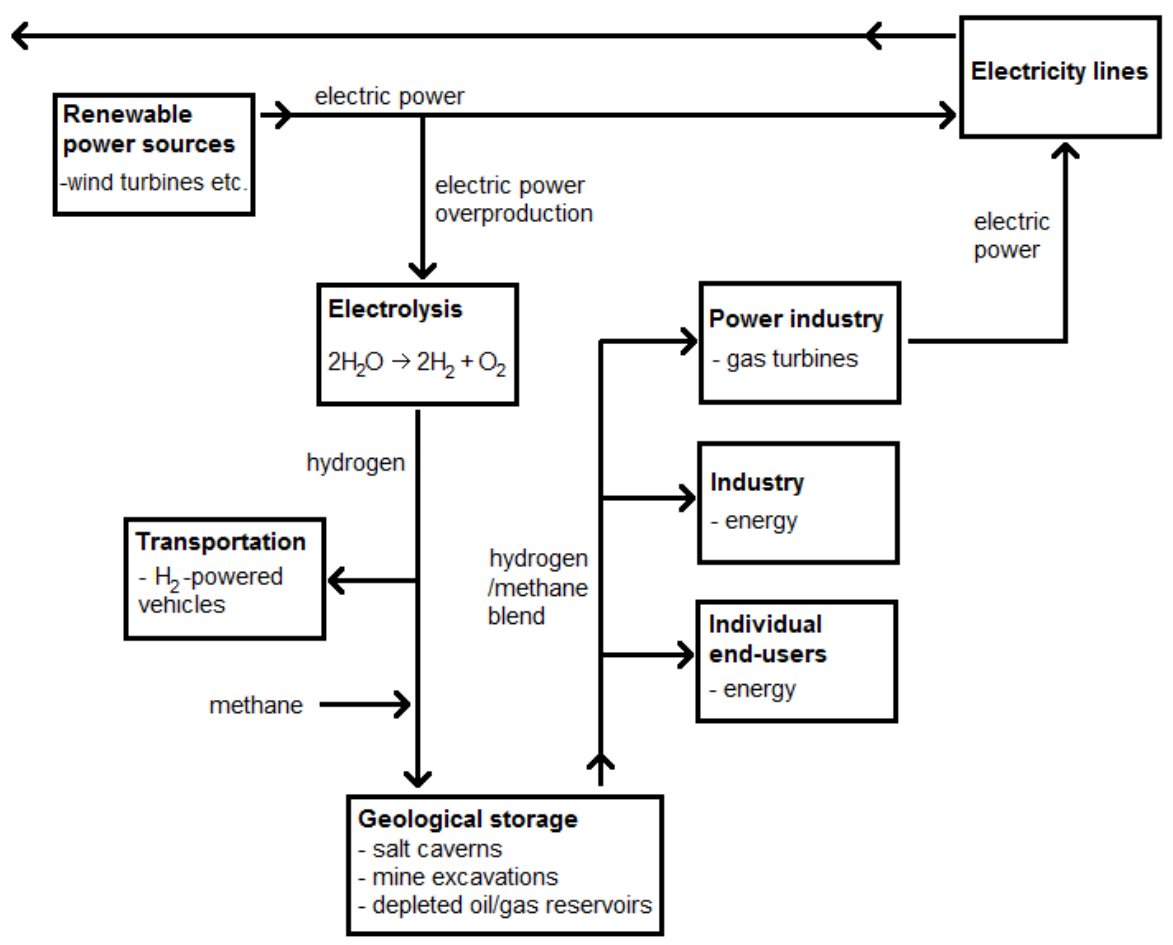

Fig. 1. Electrolysis-based hydrogen production, with possible geological storage technologies, based on (Institute of Power Engineering and Turbomachinery [Electronic resource]). 


\section{Key issues of hydrogen storage in underground mine excavations}

Storage of pure hydrogen or hydrogen - methane blends still seems to be the challenge for energy industry. Alternative method of underground storage suggested in this study is the possibility of adapting underground mine excavations for gas storage. Similar concept is being developed for Compressed Air Energy Storage [12], the possibility of storing hydrogen was suggested in other previous studies. That storage is highly desired in mine sites. Reclamation of mine areas after mine closing is always expensive and challenging issue for mine owners and local government. Adapting old mine infrastructure, including existing underground excavations and surface facilities offers an alternative solution for post mining site reclamation. Additionally, the costs of adaptation of old mine into energy storage site seems to be much cheaper than construction of the storage site in greenfield area. It eliminates the drilling, leaching and other underground works. Existing surface infrastructure and facilities, including high capacity buildings and railway sidings is add-in values for the energy storage project. Another advantage of adapting mine sites for underground energy storage is their preferred locations. Coal and ore mines are usually located in highly urbanized and industrial areas. Hydrogen can be easily transferred to local facilities, using existing pipelines and railway transportation.

Concept of hydrogen storage in abandoned underground mines does face a few challenges. One primary challenge is the sealing capacity of the underground space defined by the tightness of the storage site. Mining activity causes a huge impact on the geological structures. Most of them are crushed or fractures, especially in the nearby area of excavations (excluding shafts). The biggest challenge is to seal the excavations in a simple, efficient, and safe manner for potential gas storage projects. It is widely accepted that it is a promising solution to use the special sealing liners for resealing of the underground space with low permeability and diffusivity.

Usefulness of sealing liner will depend on the mechanical resistance of the material, because it will be exposed to possible post-mining activity like tremors and static tension. The other, and more important property will be related to gas permeability. Especially hydrogen diffusion is possible even through the intact, unfractured sample, because of the higher diffusivity of hydrogen through different materials, like steel and minerals [13, 14]. Recent research showed that diffusion of hydrogen takes place in almost every single mineral. Hydrogen diffusion ratios in selected minerals are presented in Table 1.

Table 1. Diffusion of hydrogen and oxygen in selected minerals.

\begin{tabular}{cccc}
\hline \multirow{2}{*}{ Mineral } & $\begin{array}{c}\text { Range of } \\
\text { diffusion ratios } \\
{\left[\mathrm{m}^{2} / \mathrm{s}\right]}\end{array}$ & Hydrogen & Temp. range $\left[{ }^{\mathrm{O}} \mathrm{K}\right]$ \\
\hline \multirow{2}{*}{ Quartz } & $1 * 10^{-10}-1 * 10^{-13}$ & \\
& $1 * 10^{-17}-1 * 10^{-25}$ & $1400-700$ \\
Feldspar & $1 * 10^{-11}-1 * 10^{-15}$ & $1000-500$ \\
& $1 * 10^{-16}-1 * 10^{-21}$ & $1600-600$ \\
Olivine & $1 * 10^{-9}-1 * 10^{-14}$ & $1000-700$ \\
& $1 * 10^{-16}-1 * 10^{-20}$ & $1800-1100$ \\
Pyroxenes & $1 * 10^{-10}-1 * 10^{-16}$ & $1000-600$ \\
& $1 * 10^{-16}-1 * 10^{-22}$ & $1800-1000$ \\
Amphiboles and micas & $1 * 10^{-13}-1 * 10^{-17}$ & $1100-600$ \\
& $1 * 10^{-16}-1 * 10^{-21}$ & $1100-700$ \\
\hline
\end{tabular}


The objective of this preliminary study is how the gas will migrate through the different materials. One of them, present in the underground excavations, is concrete. Ratio of that diffusion will be the main factor to evaluate the sealing properties in time and pressure functions. The goal is to elaborate the sealing material recipe, with best possible sealing properties, durability and mechanical resistance. Concept of underground excavation sealing is shown in Figure 2. Scheme presents the possible method of adapting the underground gallery by applying the sealing liner on the surfaces of the excavation. The plugs at the ends of the excavations are also necessary, which could be also made of the sealing material, with additional concrete and steel reinforcement.

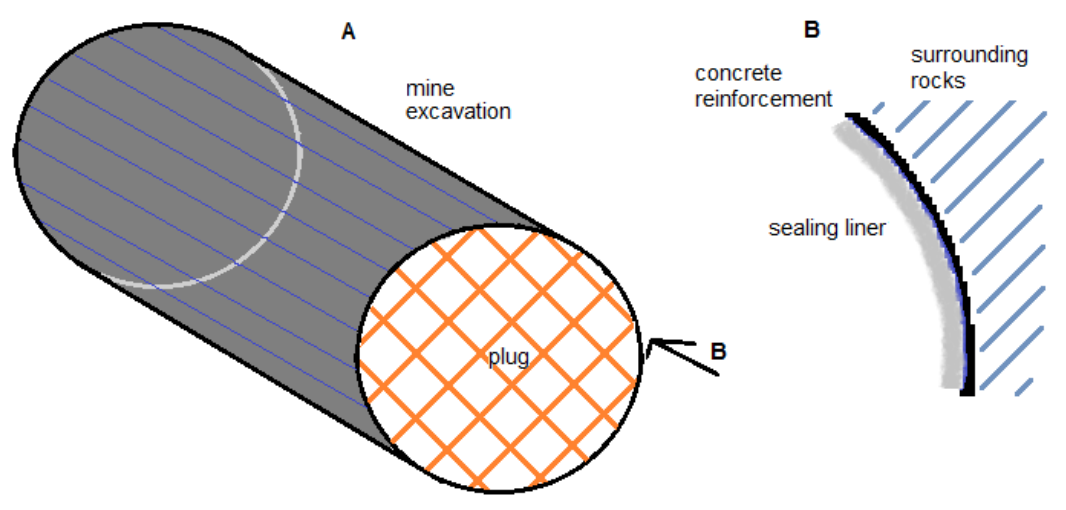

Fig. 2. The concept of sealing technology of underground excavation.

Another challenging issue is the groundwater surrounding the excavations. It is important to investigate if the groundwater presence will be helpful or harmful for the gas storage technology. Presence of the groundwater is possible outside the underground storage site. The internal space should be dry and be free of any water and moisture. Hydrostatic pressure of groundwater could be helpful for mechanical issues of underground storage, since the gas pressure inside the storage will be significant. Although it is planned to perform the research with the storage pressure of up to 20 bars, the storage pressure may be much higher than 20 bars. On the other side, presence of groundwater or brine could have a corrosive impact on the sealing liners and other underground infrastructure of the underground storage. Groundwater could be pumped from the storage area, as it takes place during the mining activity. Possibility of storing hydrogen/methane blends in abandoned underground mines have a number of advantages. That solution might be an emerging technology for the areas with no salt structures or depleted oil/gas reservoirs. It also partially solves the problem of mine areas reclamation, since the majority of surface infrastructure could be adapted for a storage site purpose.

\section{Research methodology}

Samples of concrete in this study are made of different types of concrete and other components, fly ashes and others. The mineral composition and proportions of the compounds are determining the sealing properties, and to be more precise, the gas diffusivity through the sealing liners. Subject of the laboratory research were ordinary concrete samples, as well as special geopolymers, received from a certain company. Due to the company's trade secret, composition of the geopolymers is not presented here. Properties of tested samples are shown in table 2. 
Table 2. Properties of tested samples.

\begin{tabular}{lllll}
\hline Sample & $\begin{array}{l}\text { Cement } \\
\text { type } *\end{array}$ & Additives & $\begin{array}{l}\text { Water/ } \\
\text { cement ratio }\end{array}$ & Uniaxial strength \\
\hline $\begin{array}{l}\text { Concrete sample "1" } \\
\text { Year 2019 }\end{array}$ & CEM I & Limestone 7\% & 0,47 & $17 \mathrm{MPa}$ \\
$\begin{array}{l}\text { Concrete sample "2" } \\
\text { Year 2016 }\end{array}$ & CEM II/B-S & $\begin{array}{l}\text { Furnace slag } \\
\text { (silica fumes) } \\
<35 \%\end{array}$ & n.a. & $16 \mathrm{MPa}$ \\
$\begin{array}{l}\text { Geopolymer sample "2" } \\
\text { Geopolymer sample "4" }\end{array}$ & Data is classified due to company's policy & $17-22 \mathrm{MPa}$ \\
\hline * CEM I, CEM II - cement types according to Polish Standard: PN-EN 197-1.2012, PN-B-
\end{tabular}

* CEM I, CEM II - cement types according to Polish Standard: PN-EN 197-1:2012, PN-B19707:2013.

In order to evaluate the feasibility of sealing properties of different kinds of concretes, a range of concrete samples from literature data were compared, and in addition, a few other were tested in lab using Pulse - Decay method and Steady - State Flow method.

\subsection{Pulse - Decay method}

Pulse - Decay permeability test was made in the Department of Energy and Mineral Engineering at Pennsylvania State University. Experimental setup for Pulse - Decay Method setup is shown in Figure 3. It consists of triaxial cell with water pumps, upstream and downstream reservoirs with known volume and gas cylinder [15]. Gas (helium in this study) is injected into the upstream and downstream reservoirs, with higher pressure in upstream reservoir and lower pressure in downstream side. Valve between the sample and downstream reservoir is closed during the gas injection. There is no valve between the upstream reservoir and sample, which leads to saturating of the sample with the injected gas. After reaching the equilibrium, the downstream valve is opened and the flow of the gas begins, from the upstream to downstream reservoir. After opening the downstream valve, there is a small, but instant raise of pressure in downstream reservoir, since the sample is already saturated with higher (upstream) gas pressure, and the same pressure exists between sample and closed valve on the downstream side. Flow of the gas through the sample exists, until the pressure between upstream and downstream reservoirs become equal. Water pressure applied with the independent pumps, provides the confining and axial stresses for the sample inside the core holder. 


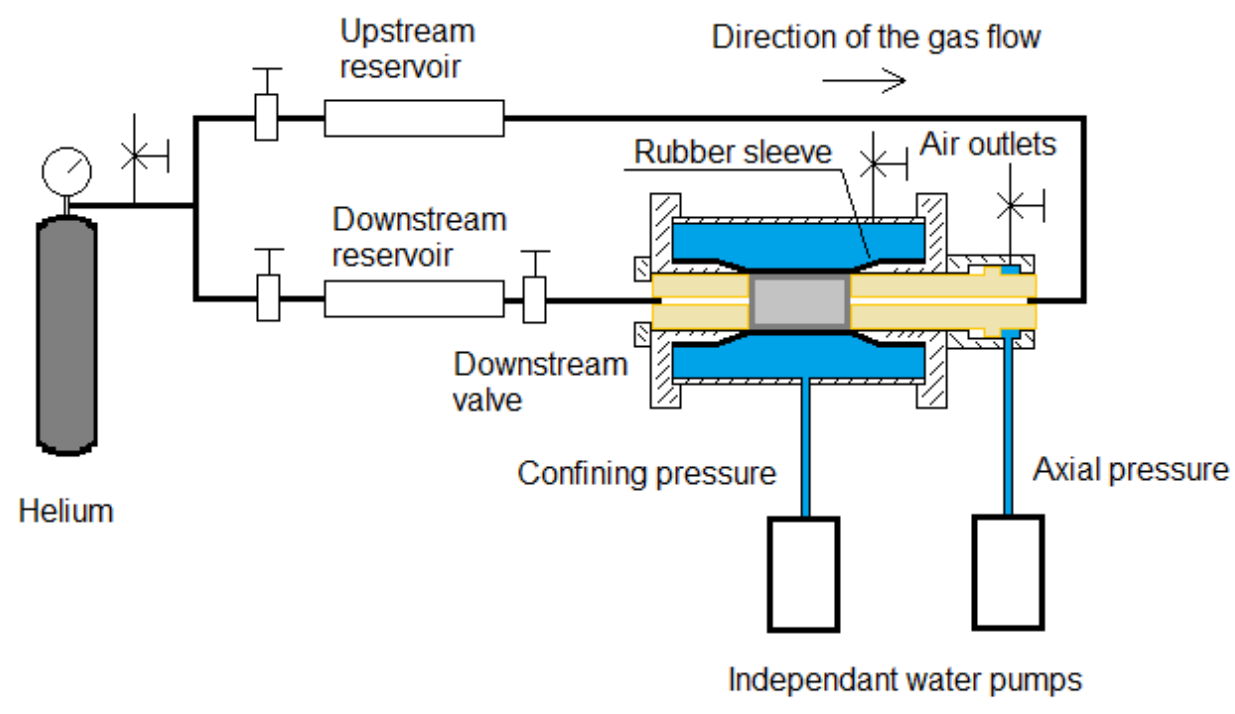

Fig. 3. Experimental setup for Pulse - Decay permeability test (Pennsylvania State University).

Range of the gas pressure used in the research were $2-12 \mathrm{MPa}$. For the lower confining/axial conditions, $4 \mathrm{MPa}, 3 \mathrm{MPa}$ and $2 \mathrm{MPa}$ were investigated. For the higher confining/axial, pressures of the gas were $12 \mathrm{MPa}, 10 \mathrm{MPa}, 8 \mathrm{MPa}$ and $6 \mathrm{MPa}$. Results shown in the table are average value from the investigated range. Results were calculated, using proper equation from.

\subsection{Steady - State Flow method}

Setup for Steady - State Flow method is shown in Figure 4. It consists of gas container. Pressure of the gas can be increased, using gas booster, powered with air compressor. Compressed gas (helium) is stored in the high-pressure chamber. Sample is hold in the rubber sleeve. Confining pressure is given with hand water pump. Opposite to the Pulse Decay method, gas here is given only on upstream side Pressure can be regulated with valve. There is also no axial stress on the sample. On the downstream side, there is a backpressure valve, providing the constant pressure on the downstream side of the sample, but lower than on the upstream side. That is causing a stable gradient of pressure across the sample. Pressure gradient were 1,5 $\mathrm{MPa}$ on the inlet and 1,0 $\mathrm{MPa}$ on the outlet. 


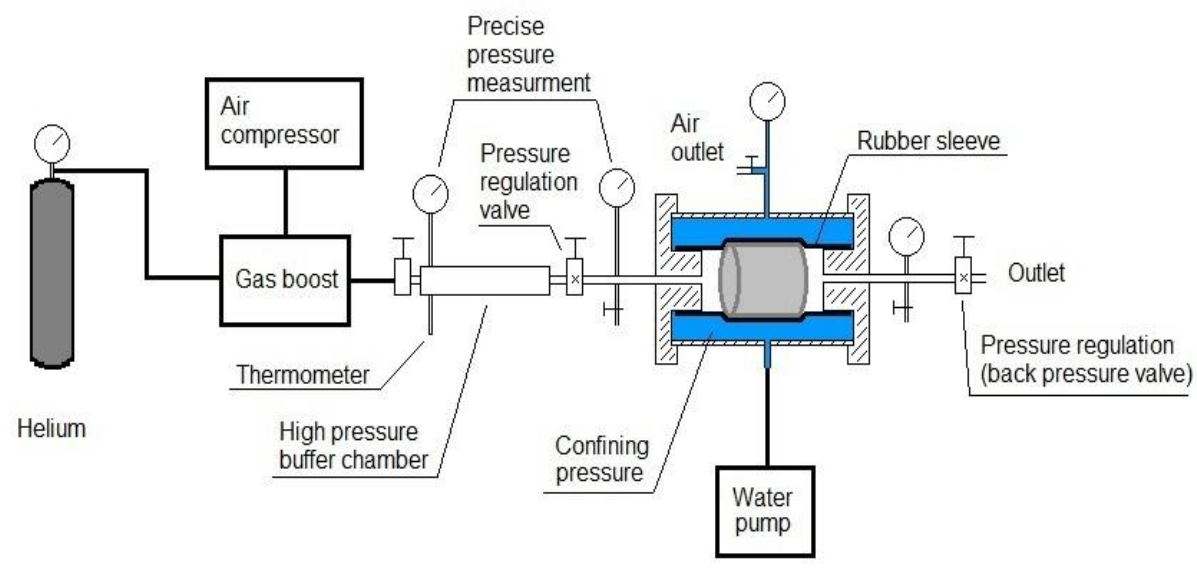

Fig. 4. Experimental setup for Steady - State Flow method (Silesian University of Technology).

Gas permeability of the sample is calculated from the difference of pressure in the chamber during the time of the test. There are known values of pressure and temperature, so it is possible to calculate the mole volume of gas.

\section{Results and discussion}

Comparison of literature data is shown in Table 3. It shows that additives, like pozzolan powders (fume dust), silica powders (containing significant amounts of $\mathrm{SiO}_{2}$ ), slags, microcement, are improving the concrete packing, which leads to decrease of the gas permeability coefficient $[16,17,18]$. Comparing the concrete based on Ordinary Portland Cement (ORD), with those with silica fumes and fly ashes, decrease of permeability of one order of magnitude is observed. Comparison of the permeability data from the Table 3 is also shown in the plot in Figure 5.

Table 3. Comparison of permeability of selected concretes with different additives.

\begin{tabular}{|c|c|c|c|c|c|}
\hline Sample & $\begin{array}{l}\text { Cement } \\
\text { type }\end{array}$ & Additives & $\begin{array}{l}\text { Water/ } \\
\text { concrete } \\
\text { ratio }\end{array}$ & Porosity, \% & $\begin{array}{l}\text { Gas permeability, } \\
\mathrm{mD} / \mathrm{m}^{2}\end{array}$ \\
\hline $\mathrm{OPC}$ & $\begin{array}{l}\text { Ordinary } \\
\text { Portland } \\
\text { Cement }\end{array}$ & - & n.a. & n.a. & $\begin{array}{l}0,01 \\
1 * 10^{-17}\end{array}$ \\
\hline OPC-FA & $\begin{array}{l}\text { Ordinary } \\
\text { Portland } \\
\text { Cement }\end{array}$ & Fly ash $30 \%$ & n.a. & n.a. & $\begin{array}{l}0,001 \\
1 * 10^{-18}\end{array}$ \\
\hline OPC-SF & $\begin{array}{l}\text { Ordinary } \\
\text { Portland } \\
\text { Cement }\end{array}$ & Silica fumes $10 \%$ & n.a. & n.a. & $\begin{array}{l}0,001 \\
1 * 10^{-18}\end{array}$ \\
\hline $\mathrm{HPC}$ & $\begin{array}{l}\text { CEM II } \\
52,5\end{array}$ & Plasticizer & 0,31 & 8,5 & $\begin{array}{l}0,0001 \\
1 * 10^{-19} \text { (20 days) } \\
0,01 \\
1 * 10^{-17}(100 \text { days })\end{array}$ \\
\hline
\end{tabular}




\begin{tabular}{llllll}
\hline PCC 5 & CEM I & SBR 5\% & 0,43 & n.a. & 0,1 \\
& 32,5 & & & & $1 * 10^{-16}$ \\
PCC 15 & CEM I & SBR 15\% & 0,32 & n.a. & 0,0001 \\
& 32,5 & & & & $1 * 10^{-19}$ \\
PCC 20 & CEM I & SBR 20\% & 0,28 & n.a. & Impermeable* \\
& 32,5 & & & & \\
\hline
\end{tabular}

*Unable to carry out the measurement due to setup sensitivity.

CEM I, CEM II - cement types according to Polish Standard: PN-EN 197-1:2012, PN-B-19707:2013.

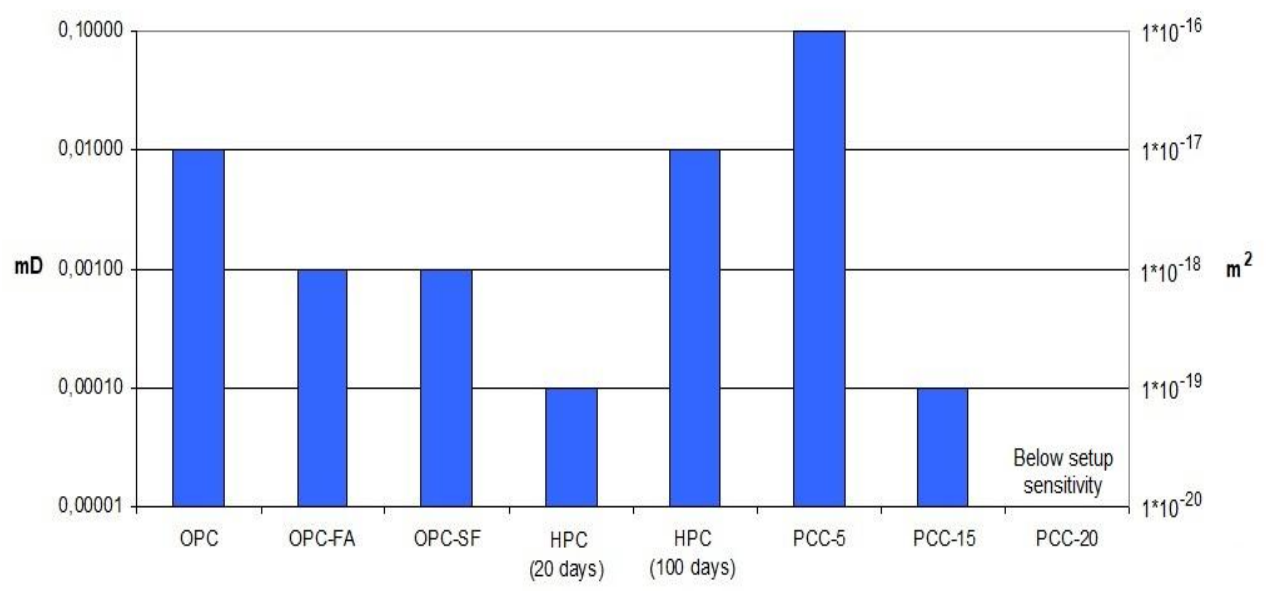

Fig. 5. Comparison of permeability of different concrete samples.

Decrease of permeability shown in Table 3 is caused by filling of the free spaces in concrete structures with additives of micro grain sizes. Scheme of that phenomena is illustrated in Figure 6 [19]. In addition, high-strength concretes are much less permeable than ordinary concretes, due to more dense packing of the components and grains. It is shown in Table 3 on an example of High Performance Concrete (HPC).

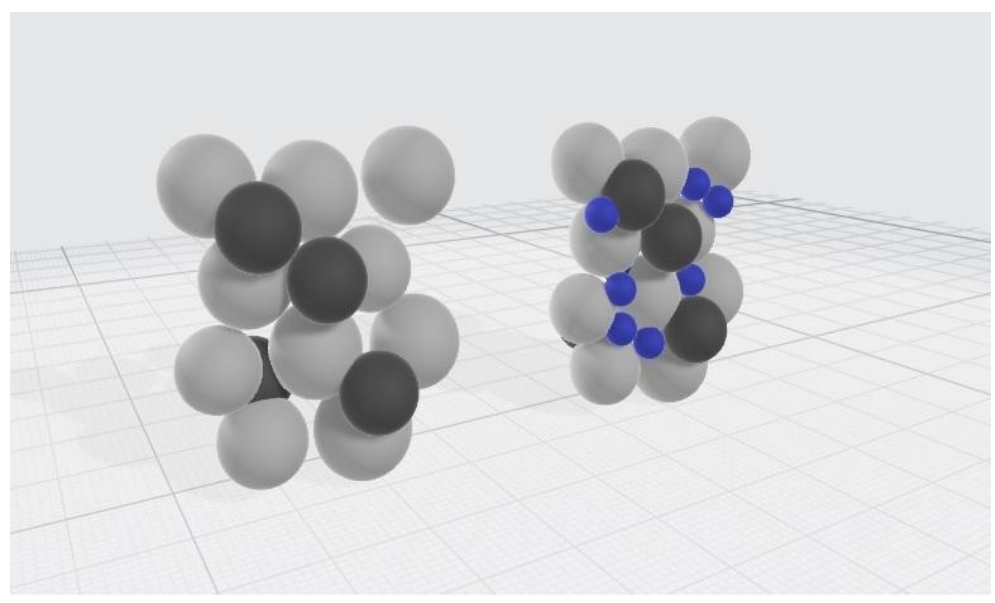

Fig. 6. Scheme of microstructure of concrete and impact of fine size additives on the tightness of the structure, based on. 
Obtained results from Pulse - Decay test and Steady - State Flow test in Table 4 show, that permeability of investigated concrete and geopolymers sample depend on the composition, but also the confining pressure. The factor causing that variation, apart from fine size additives, that increases the impermeability, is the surrounding pressure given by axial stress in Pulse - Decay Method. Results showed that higher confining pressure and axial stress on sample during the Pulse - Decay test, decreases the permeability significantly. The same samples tested with Steady - State method on comparable confining stress, but with no axial stress are much more permeable. This phenomenon is caused by higher structure packing from mechanical stress put on the sample. Only geopolymers' permeability from these two methods were on the comparable level, with only small influence of axial stress on the permeability of the samples. The reason of smaller influence of axial stress on the permeability may be the higher uniaxial strength of the geopolymers, comparing to the conventional concretes. Due to the higher resistance, the structure is not changing that much from the axial stress, which causes only a small decrease of the permeability. Variation of the samples' permeability is shown in the plot in Figure 7.

Table 4. Comparison of permeability of tested concretes and geopolymers from pulsedecay method and steady-state flow method, using helium.

\begin{tabular}{|c|c|c|c|}
\hline \multirow[t]{3}{*}{ Sample } & \multicolumn{3}{|c|}{ Gas permeability, $\mathrm{mD} / \mathrm{m}^{2}$} \\
\hline & \multicolumn{2}{|c|}{ Steady - State Flow method } & Pulse - Decay method \\
\hline & $\begin{array}{l}\text { Confining/axial stress } \\
4 \mathrm{MPa} / \text { none }\end{array}$ & $\begin{array}{l}\text { Confining/axial stress } \\
5 \mathrm{MPa} / 4 \mathrm{MPa}\end{array}$ & $\begin{array}{l}\text { Confining/axial stress } \\
15 \mathrm{MPa} / 14 \mathrm{MPa}\end{array}$ \\
\hline $\begin{array}{l}\text { Concrete sample } \\
\text { "1" } \\
\text { (year 2019) }\end{array}$ & $\begin{array}{l}0,0505 \\
4,990 * 10^{-17}\end{array}$ & $\begin{array}{l}0,0028 \\
2,764 * 10^{-18}\end{array}$ & $\begin{array}{l}0,0009 \\
8,609 * 10^{-19}\end{array}$ \\
\hline $\begin{array}{l}\text { Concrete sample } \\
\text { "2" } \\
\text { (year 2016) }\end{array}$ & $\begin{array}{l}0,2703 \\
2,670^{*} 10^{-16}\end{array}$ & $\begin{array}{l}0,0198 \\
1,954 * 10^{-17}\end{array}$ & $\begin{array}{l}0,0033 \\
3,300 * 10^{-18}\end{array}$ \\
\hline $\begin{array}{l}\text { Geopolymer } \\
\text { samples } \\
\text { "2" and " } 4 \text { " } \\
\text { (year 2019) }\end{array}$ & $\begin{array}{l}0,0641 \\
6,330 * 10^{-17}\end{array}$ & $\begin{array}{l}0,0403 \\
3,971 * 10^{-17}\end{array}$ & $\begin{array}{l}\text { Samples were crushed } \\
\text { with the confining/axial } \\
\text { stress }\end{array}$ \\
\hline
\end{tabular}




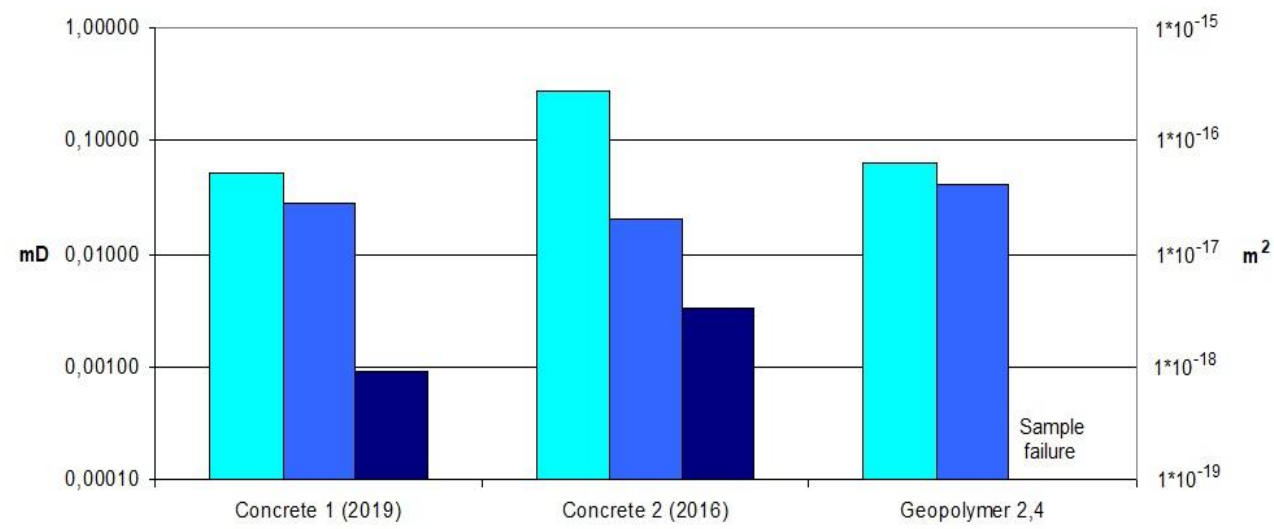

Confining/axial stress: $\square 4 \mathrm{MPa} / 0 \mathrm{MPa}$ (Steady - State) $\square 5 \mathrm{MPa} / 4 \mathrm{MPa}$ (Pulse - Decay) ■15 MPa/14 MPa (Pulse-Decay)

Fig. 7. Variation of the permeability, caused by the different confining and axial stress.

Permeability results from both literature and our experiment study demonstrate that conventional concretes with mineral powder additives can have a small gas permeability, but are not tight enough for the gas sealing purposes, especially hydrogen. All of the ordinary concretes seem to have a top impermeability value of around $10^{-19} \mathrm{~m}^{2}$, that cannot be override with any powder additives. The same conclusions are made from analyzing the Pulse - Decay results of samples selected from the investigated ones. Performing the hydrogen diffusion test on that kind of permeable samples is unjustified.

The significant decrease of permeability, up to the values above the setup sensitivity, can be achieved with the synthetic additives. SBR Rubber causes the significant change of gas permeability, and the amount of $15-20 \%$ is making the concrete impermeable (below $10^{-20} \mathrm{~m}^{2}$ ). Although ordinary concrete can be a mechanical base for the sealing concstuction in the underground gas depot, they need to be covered with liner of material with better sealing properties, like steel or resins. Literature data show, that use of the synthetic additives, like SBR rubber can make the concrete impermeable for gas.

\section{Summary}

Hydrogen from renewable energy sources overproduction is a promising way of excess energy storage, considering constant development of electrolyzers for hydrogen production. Hydrogen can be piped and stored at low concentrations in existing natural gas infrastructure, with only a minor changes to gas transportation and gas - powered equipment. However, since most of currently operating storage sites, except salt caverns, are strongly limited for hydrogen purposes, seeking the alternative ways of storing hydrogen/methane blends is highly desired.

There are a few challenges of adapting the underground mine excavation for the hydrogen/methane storage sites. First of them is sealing the underground space in a durable and safe way. The sealing should be resistant to the possible post-mining activity like tremors and static tension. It is important to prevent a major failures, which might be dangerous for the surrounding urbanized areas. Other challenging issue is the hydrogen diffusion through the sealing liners.

Article show, that conventional concretes are not tight enough for the gas sealing purpose, especially for hydrogen. That kind of concretes, despite of the additives, seem to have the top impermeability value, which is not possible to transcend. It is also pointed out, 
that gas permeability of concrete depend on the composition of the concrete, but also on pressure conditions that impact on the concrete structure.

Polymer concretes and resins are much more useful for underground storage. Although these materials can be tight enough for other gases, like methane or compressed air, hydrogen might still diffuse through their structure, due to hydrogen's ability to permeate into the molecular structure of materials. Despite of their's impermeability for gases, they should be tested for hydrogen diffusion as well. These sealing materials and hydrogen diffusion phenomena are the subject of current research at the Laboratory of Unconventional Gas and $\mathrm{CO}_{2}$ Storage at the Silesian University of Technology.

Publication supported by Own Scholarship Fund of the Silesian University of Technology in year 2018/2019, grant number: 1/WFS18/0003-04/201.

\section{References}

1. Commercialisation of Energy Storage in Europe. 2015. Fuel Cells and Hydrogen Joint Undertaking (FCH JU) Final Report, March 2015 [Electronic resource]. - Access mode: http://www.fch.europa.eu

2. C.J. Winter, J. Nitsch, Hydrogen as an Energy Carrier: Technologies, Systems, Economy (Springer-Verlag, 1988).

3. M.W. Melaina, O. Antonia, M. Penev, Blending hydrogen into natural gas pipeline networks: A review of key issues (Technical Report of National Renew. Ener. Lab. US Dept. of Energy, 2013).

4. K. Altfeld, D. Pinchbeck, Admissible hydrogen concentrations in natural gas system. Gas for Energy, 3/2013 (reprint) (2013).

5. M. Chaczykowski, A.J. Osiadacz, Energet. Gaz. 2016 - Mater. VI konf. nauk.-tech.ed. Ł. Bartela et. al. (Gliwice: Inst. Tech. Ciepl.): 33-46. (2016).

6. V. Reitenbach, et. al.. Environ. Earth Sci. 7: 6927-37. (2015)

7. A.S. Lord, Overview of geologic storage of natural gas with an emphasis on assessing the feasibility of storing hydrogen. (Technical Report of Scandia National Lab. US Dept. of Energy, 2009).

8. P. Jalili, S. Saydam, Y. Cinar, CO2 Storage in Abandoned Coal Mines. 11th Underground Coal Operators' Conference, University of Wollongong and the Australasian Institute of Mining and Metallurgy 2011: 355-360. (2011).

9. A.Kunstman, K. Urbańczyk, Salt Review 2013. ed. J. Wachowiak (Kraków: Polish Salt Mining Assoc.): 20-25. (2013).

10. M. Kaliski, A. Sikora, Salt Review 2013. ed. J. Wachowiak (Kraków: Polish Salt Mining Assoc.): 26-32. (2013).

11. Website of Institute of Power Engineering and Turbomachinery, Silesian Univer. of Tech. [Electronic resource]. http://www.imiue.polsl.pl/index.php?cPath=159_169_300_391\&language=en (accessed date 08/2020).

12. M. Lutyński, An overview of potential benefits and limitations of Compressed Air Energy Storage in abandoned coal mines IOP Conf. Ser.: Mater. Sci. Eng. 268012006 (2017)

13. A.S. Lord, H. Kobos, D. Borns, Geologic Storaged of Hydrogen. Presentation of Scandia National Lab. US Dept. of Energy. (2009). 
14. J.R. Farver, Oxygen and Hydrogen Diffusion in Minerals. Rev. in Mineral. and Geochem.72: 447-507. (2010).

15. Y. Wang, S. Liu, D. Elsworth, Laboratory investigations of gas flow behaviors in tight anthracite and evaluation of different pulse - decay methods on permeability estimation. Internat. Jour. of Coal Geology. 149: 118-128. (2015).

16. B. Chmielewska, Effect of polymer additive on gas permeability coefficient of concrete. Advances Materials Research. 687: 191-197. (2013).

17. K.E. Hassan, J.G. Cabrera, R.S. Maliehe, The effect of mineral admixtures on the properties of high-performance concrete Cement and Concrete Composites. 22: 267271. (2000).

18. D. Quenard, M. Carcasses, Gas permeability of concrete: definition of a preconditioning procedure for measurements and crossover trials. Durability of Building Materials and Components. 8: 236-245. (1999).

19. M. Kremieniewski, Modyfikacja przestrzeni porowej kamieni cementowych, NaftaGaz: 165-170. (2012). 